\title{
Analisis Radiasi Hambur di Luar Ruangan Klinik Radiologi Medical Check Up (MCU)
}

\author{
Muh. Zakky Arizal ${ }^{1}$, Budi Santoso ${ }^{1}$, Dwi Bondan Panular ${ }^{2}$, Febria Anita ${ }^{1}$ \\ ${ }^{1}$ Program Studi Fisika, Fakultas Teknik dan Sains, Universitas Nasional, Jakarta \\ ${ }^{2}$ Fisika Medik, RSPAD Gatot Soebroto, Jakarta \\ Korespondensi : profbudis@yahoo.com
}

\begin{abstract}
ABSTRAK. Telah dilakukan penelitian tentang Analsisis Radiasi Hambur di Luar Ruangan Klinik Radiologi Medical Check Up (MCU). Penelitian ini bertujuan untuk mengetahui dosis radiasi hambur yang diterima titik perisai dan Pola sebaran radiasi hambur di belakang titik perisai. Penelitian ini menggunakan surveymeter sebagai alat ukur radiasi. Proses pengambilan data dilakukan dengan cara peneliti berdiri dibelakang dinding setiap dilakukan pemeriksaan dengan faktor eksposi yang sudah ditentukan yaitu 50, 55, dan 60 $\mathrm{kV}$ dengan waktu $16 \mathrm{mAs}$. Pengambilan data dilakukan dengan beberapa kali agar datamenjadi lebih akurat. Hasil dari penelitian ini adalah didapatkan laju dosis radiasi sebesar 0,477, 0,76, dan 0,897mSv/tahun masih jauh dari nilai batas dosis untuk pekerja radiasi $20 \mathrm{mSv}$ dan masyarakat umum $1 \mathrm{mSv}$. Pola sebaran radiasi hambur kenaikan yang signifikan ditujukan oleh dinding penahan yang merupakan shielding $\mathrm{F}$ yang terletak di didalam ruangan untuk tempat berlindungnya petugas radiasi ketika melakukan pemeriksaan.
\end{abstract}

Kata kunci: Shielding, Surveymeter, Dosis Radiasi, Faktor Eksposi.

\begin{abstract}
Analysis of Scattered radiation outside the radiology medical check up $(M C U)$ room. This study aims to determine the radiation dose received scatter shield point and distribution pattern in the back-scattered radiation shield poin. This study uses surveymeter as a measure of radiation. The process of data collection wa done by researchers stand behind the wall of each examination with eksposi fctor that has been determined as 50,55, and $60 \mathrm{kV}$ with a time of mAs. Data were collected by several times to make the data more accurate. The results of this study are obtained radiation dose rate of 0.477, 0.76 and $0.897 \mathrm{mSv} /$ year is still far from the value of the dose limit for radiation workers and the general publick $20 \mathrm{mSv} 1 \mathrm{mSv}$. The distribution pattern of scattered radiation increased significantly addressed by a retaining wall which is shielding $F$ located inside the room for a refuge clerk radiation when scanning.
\end{abstract}

Keywords: shielding, Surveymeter, Radiation Dose, Factor Exposure.

\section{PENDAHULUAN}

Sinar X adalah pancaran gelombang elektromagnetik yang sejenis dengan gelombang radio, panas, cahaya, dan sinar ultraviolet, dan memiiki panjang gelombang yang cenderung sangat pendek $10^{-8}$ sampai dengan $10^{-11} \mathrm{~m}$, akan tetapi memiliki energi yang sangat besar. Kemampuan sinar $\mathrm{X}$ menembus bahan sering kali dimanfaatkan pada bidang medis salah satunya ranah radiodiagnostik. Pemanfaatan sinar $\mathrm{X}$ telah di atur dengan standar internasional yaitu oleh IAEA dan BAPETEN yang meliputi asas-asas proteksi radiasi dan penerimaan dosis radiasi untuk mengutamakan aspek keselamatan terhadap individu, masyarakat dan lingkungan dari bahaya radiasi. pekerja radiasi terdiri atas operator, supervisor, pekerja sistem bantu, petugas proteksi radiasi, maupun pekerja radiasi selain tersebut di atas. Masyarakat (publik) adalah manusia bukan pekerja radiasi yang ada di luar kawasan instalasi radiologi [1].

Menurut PERKA BAPETEN Nomor 4 Tahun 2013 yang mengatur Proteksi dan Keselamatan Radiasi dalam Pemanfaatan Tenaga Nuklir, pekerja radiasi tidak boleh menerima dosis radiasi melebihi $50 \mathrm{mSv}$ pertahun dan rata-rata pertahun tidak boleh lebih dari $20 \mathrm{mSv}$. Sedangkan masyarakat umum tidak boleh menerima lebih dari $1 \mathrm{mSv}$ pertahun. Karena bagaimanapun radiasi akan memiliki efek biologi yang meliputi efek non stokastik dan stokastik [2]. 
Dalam suatu instalasi untuk penggunaan sumber radiasi, konstruksi gedung yang digunakan mempunyai fungsi sebagai penahan radiasi. Persyaratan penahan radiasi bagi ruangan radiodiagnostik tergantung pada jenis peralatan dan energi radiasi yang dipakai [3].

\section{BAHAN DAN METODE}

Pengambilan data dilakukan dengan alat survermeter sebagai alat pendeteksi radiasi hambur dan pesawat X-ray mobile sebagai sumber sinar-X. Di ruang radiologi peneliti mengukur jarak sumber sinar-X ke masing-masing dinding yang sudah di tandai dengan kode huruf A,B,C,D,E, dan F. Peneliti penggunakan surveymeter dan ditempatkan di balik perisai yang menghadap ke sumber sinar $\mathrm{X}$ dan berada 1 meter di atas lantai. Faktor eksposi yang digunakan pada penelitian ini adalah sumber radiasi dengan tegangan sebesar 50,55, $60 \mathrm{kV}$ dan menggunakan waktu 16 mAs.

Dalam penelitian ini diawali dengan melakukan menempatkan pesawat $X$-ray mobile menghadap dinding A dan selanjutnya dilakukan pengukuran jarak sumber radiasi dengan dinding dan shielding. Ketebalan dinding dan perisai diukur menggunakan meteran. Kemudian faktor eksposi disesuaikan dengan faktor eksposi yang sudah ditentukan. Setelah faktor eksposi sudah siap dilanjutkan untuk menyiapkan surveymeter yang sudah terkalibrasi untuk dilakukan pengambilan data laju paparan radiasi hambur dibalik dinding dan shielding yang sudah ditentukan. Pengambilan data dilakukan beberapa kali untuk mendapatkan hasil yang akurat. Setelah diperoleh data dosis hambur dilakukan perbandingan dengan Nilai Batas Dosis (NBD) yang ditetapkan oleh BAPETEN yaitu sebesar $20 \mathrm{mSv} /$ tahun untuk petugas radiasi dan 1 $\mathrm{mSv} / \mathrm{tahun}$ untuk masyarakat umum.

\section{HASIL DAN PEMBAHASAN}

Penelitian dilakukan di Unit Radiologi Klinik Medical Check Up (MCU) Fatmawati Jakarta Selatan. Pertama yang dilakukan dalam penelitian ini peneliti melakukan pengukuran luas ruangan, tebal dan tinggi penahan yang akan digunakan sebagai penahan radiasi yang diperlihatkan pada gambar 1.

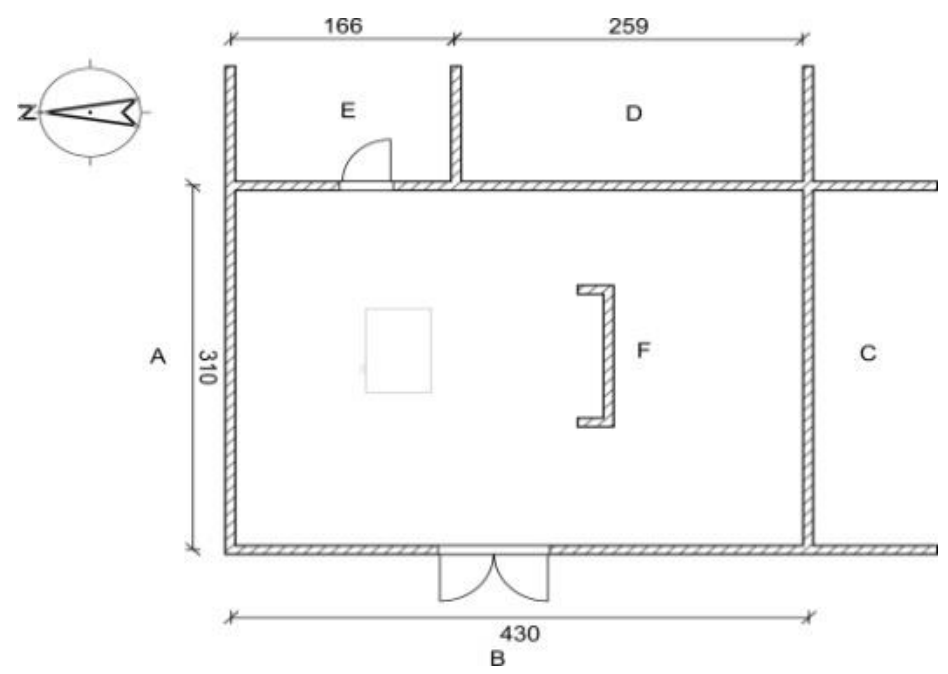

GAMBAR 1. Denah ruang pemeriksaan di Instalasi Radiologi.

Keterangan : (A) Tanah Kosong (Dinding A), (B) Ruang Tunggu (Dinding B), (C) Kantor (Dinding C), Kamar Mandi (Dinding D), (E) Kamar Gelap (Dinding E), (F) Mobile Shielding (Dinding F)

Luas ruang pemeriksaan keseluruhan dapat dihitung dengan panjang $430 \mathrm{~cm} \times 1$ ebar $310 \mathrm{~cm}=$ $133300 \mathrm{~cm}^{2}$. Tinggi ruang pemeriksaan $300 \mathrm{~cm}$. Dengan luas keseluruhan hasil perhitungan dapat dilihat dalam tabel 1 . 
TABEL 1. Luas Ruang Pemeriksaan

\begin{tabular}{|c|c|c|}
\hline No & Parameter & Ukuran (cm) \\
\hline 1 & Panjang (P) & 430 \\
\hline 2 & Lebar (L) & 310 \\
\hline 3 & Tinggi (T) & 300 \\
\hline 4 & $\begin{array}{c}\text { DimensiRuang (cm) } \\
\text { (P x L x T) }\end{array}$ & 39990000 \\
\hline 5 & $\begin{array}{c}\text { Luas (cm2) } \\
(\mathrm{P} \mathrm{x} \mathrm{L)}\end{array}$ & 133300 \\
\hline
\end{tabular}

Pengukuran jarak antara sumber radiasi dengan masing-masing dinding yang dilakukan diperlihatkan dalam tabel 2.

TABEL 2. Jarak antara sumber radiasi dengan dinding

\begin{tabular}{|c|c|c|}
\hline No. & Dinding & Jarak (cm) \\
\hline 1 & A & 170 \\
\hline 2 & B & 160 \\
\hline 3 & C & 260 \\
\hline 4 & D & 200 \\
\hline 5 & E & 150 \\
\hline 6 & F & 200 \\
\hline
\end{tabular}

Dalam pembuatan sebuah dinding primer maupun sekunder diperlukan perhitungan beban kerja (workload). Untuk menghitung beban kerja dilakukan pengambilan data pasien terbanyak dalam 4 minggu yang di ambil dari data pasien bulan April sampai Mei 2015. Data eksposi kemudian dikalikan dengan faktor eksposi tertinggi yang digunakan dalam waktu pemeriksaan yaitu 60 $\mathrm{kV}$ denga 16 mAs. Hasil perhitungan kemudian dibagi sebanyak 4 minggu dalam pengambilan data pasien yang digunakan. Dari hasil perhitungan di atas diperoleh data pada Tabel 3.

TABEL 3. Hasil Pernghitungan Beban Kerja (workload)

\begin{tabular}{|c|c|c|}
\hline No. & Mingguke- & JumlahPasien \\
\hline 1 & I & 19 \\
\hline 2 & II & 32 \\
\hline 3 & III & 25 \\
\hline 4 & IV & 31 \\
\hline Total Pasien & 107 \\
\hline mAsTertinggi & 16 \\
\hline$\sum$ mAs & 1712 \\
\hline mAs/minggu & 428 \\
\hline mA.menit/minggu & 7,133 \\
\hline
\end{tabular}

Dari perhitungan tebal dinding minimal dalam penyerapan didapatkan hasil dan nilai seperti pada tabel 4.

Tabel 4. Data Ketebalan Dinding di Ruang Radiologi

\begin{tabular}{|c|c|c|c|}
\hline No & Dinding & Dinding yang ada & DindingHasilPerhitungan \\
\hline 1 & $\mathrm{~A}$ & $2 \mathrm{~mm} \mathrm{~Pb}+14$ bataplester & $0,8 \mathrm{~mm} \mathrm{~Pb}+5,82$ bataplester \\
\hline 2 & $\mathrm{~B}$ & $2 \mathrm{~mm} \mathrm{~Pb}+14$ bataplester & $0,7 \mathrm{~mm} \mathrm{~Pb}+5,2$ bataplester \\
\hline 3 & $\mathrm{C}$ & $2 \mathrm{~mm} \mathrm{~Pb}+14$ bataplester & $0,3 \mathrm{~mm} \mathrm{~Pb}+2,02$ bataplester \\
\hline 4 & $\mathrm{D}$ & $2 \mathrm{~mm} \mathrm{~Pb}+14$ bataplester & $0,6 \mathrm{~mm} \mathrm{~Pb}+4,35$ bataplester \\
\hline 5 & $\mathrm{E}$ & $2 \mathrm{~mm} \mathrm{~Pb}+14$ bataplester & $0,8 \mathrm{~mm} \mathrm{~Pb}+5,81$ bataplester \\
\hline 6 & $\mathrm{~F}$ & $2 \mathrm{~mm} \mathrm{~Pb}$ & $0,4 \mathrm{~mm} \mathrm{~Pb}$ \\
\hline
\end{tabular}

Laju dosis radiasi hambur yang didapat dari hasil pengukuran menggunakan surveymeter dengan faktor eksposi 50, 55, $60 \mathrm{kV}$ dan $16 \mathrm{mAs}$ dengan hasil sebagai berikut pada tabel 5, 6 dan 7. 
TABEL 5. Hasil Pengukuran dengan $50 \mathrm{kV} 16 \mathrm{mAs}$

\begin{tabular}{|c|c|c|c|c|}
\hline No & Dinding & $\begin{array}{c}\text { Hasil Ukur } \\
\mathbf{5 0} \mathbf{~ k V}\end{array}$ & $\begin{array}{c}\text { Dikalikan Faktor Kalibrasi } \\
\mathbf{1 , 0 1}\end{array}$ & $\begin{array}{c}\text { Laju Paparan Hambur } \\
\text { per Tahun }\end{array}$ \\
\hline 1 & $\mathrm{~A}$ & $2,99 \times 10^{-4} \mathrm{mSv} / \mathrm{hr}$ & $3,02 \times 10^{-4} \mathrm{mSv} / \mathrm{hr}$ & $0,638 \mathrm{mSv} / \mathrm{tahun}$ \\
\hline 2 & $\mathrm{~B}$ & $2,31 \times 10^{-4} \mathrm{mSv} / \mathrm{hr}$ & $2,33 \times 10^{-4} \mathrm{mSv} / \mathrm{hr}$ & $0,485 \mathrm{mSv} / \mathrm{tahun}$ \\
\hline 3 & $\mathrm{C}$ & $0,77 \times 10^{-4} \mathrm{mSv} / \mathrm{hr}$ & $0,77 \times 10^{-4} \mathrm{mSv} / \mathrm{hr}$ & $0,162 \mathrm{mSv} / \mathrm{tahun}$ \\
\hline 4 & $\mathrm{D}$ & $2 \times 10^{-4} \mathrm{mSv} / \mathrm{hr}$ & $2,02 \times 10^{-4} \mathrm{mSv} / \mathrm{hr}$ & $0,42 \mathrm{mSv} / \mathrm{tahun}$ \\
\hline 5 & $\mathrm{E}$ & $2,29 \times 10^{-4} \mathrm{mSv} / \mathrm{hr}$ & $2,31 \times 10^{-4} \mathrm{mSv} / \mathrm{hr}$ & $0,481 \mathrm{mSv} / \mathrm{tahun}$ \\
\hline 6 & $\mathrm{~F}$ & $2,27 \times 10^{-4} \mathrm{mSv} / \mathrm{hr}$ & $2,29 \times 10^{-4} \mathrm{mSv} / \mathrm{hr}$ & $0,477 \mathrm{mSv} / \mathrm{tahun}$ \\
\hline
\end{tabular}

TABEL 6. Hasil Pengukuran dengan $55 \mathrm{kV} 16 \mathrm{mAs}$

\begin{tabular}{|c|c|c|c|c|}
\hline No & Dinding & $\begin{array}{c}\text { Hasil Ukur } \\
\mathbf{5 5} \mathbf{~ k V}\end{array}$ & $\begin{array}{c}\text { Dikalikan Faktor Kalibrasi } \\
\mathbf{1 , 0 1}\end{array}$ & $\begin{array}{c}\text { Laju Paparan Hambur per } \\
\text { Tahun }\end{array}$ \\
\hline 1 & $\mathrm{~A}$ & $3,57 \times 10^{-4} \mathrm{mSv} / \mathrm{hr}$ & $3,6 \times 10^{-4} \mathrm{mSv} / \mathrm{hr}$ & $0,75 \mathrm{mSv} /$ tahun \\
\hline 2 & $\mathrm{~B}$ & $3,53 \times 10^{-4} \mathrm{mSv} / \mathrm{hr}$ & $3,56 \times 10^{-4} \mathrm{mSv} / \mathrm{hr}$ & $0,741 \mathrm{mSv} / \mathrm{tahun}$ \\
\hline 3 & $\mathrm{C}$ & $0,97 \times 10^{-4} \mathrm{mSv} / \mathrm{hr}$ & $0,98 \times 10^{-4} \mathrm{mSv} / \mathrm{hr}$ & $0,204 \mathrm{mSv} / \mathrm{tahun}$ \\
\hline 4 & $\mathrm{D}$ & $2,31 \times 10^{-4} \mathrm{mSv} / \mathrm{hr}$ & $2,33 \times 10^{-4} \mathrm{mSv} / \mathrm{hr}$ & $0,485 \mathrm{mSv} / \mathrm{tahun}$ \\
\hline 5 & $\mathrm{E}$ & $3,4 \times 10^{-4} \mathrm{mSv} / \mathrm{hr}$ & $3,43 \times 10^{-4} \mathrm{mSv} / \mathrm{hr}$ & $0,714 \mathrm{mSv} / \mathrm{tahun}$ \\
\hline 6 & $\mathrm{~F}$ & $3,62 \times 10^{-4} \mathrm{mSv} / \mathrm{hr}$ & $3,65 \times 10^{-4} \mathrm{mSv} / \mathrm{hr}$ & $0,76 \mathrm{mSv} / \mathrm{tahun}$ \\
\hline
\end{tabular}

TABEL 7. Hasil Pengukuran dengan $60 \mathrm{kV} 16 \mathrm{mAs}$

\begin{tabular}{|c|c|c|c|c|}
\hline No & Dinding & $\begin{array}{c}\text { Hasil Ukur } \\
\mathbf{5 5} \mathbf{~ k V}\end{array}$ & $\begin{array}{c}\text { Dikalikan Faktor Kalibrasi } \\
\mathbf{1 , 0 1}\end{array}$ & $\begin{array}{c}\text { Laju Paparan Hambur per } \\
\text { Tahun }\end{array}$ \\
\hline 1 & $\mathrm{~A}$ & $4,58 \times 10^{-4} \mathrm{mSv} / \mathrm{hr}$ & $4,63 \times 10^{-4} \mathrm{mSv} / \mathrm{hr}$ & $0,962 \mathrm{mSv} / \mathrm{tahun}$ \\
\hline 2 & $\mathrm{~B}$ & $3,83 \times 10^{-4} \mathrm{mSv} / \mathrm{hr}$ & $3,87 \times 10^{-4} \mathrm{mSv} / \mathrm{hr}$ & $0,805 \mathrm{mSv} / \mathrm{tahun}$ \\
\hline 3 & $\mathrm{C}$ & $1,03 \times 10^{-4} \mathrm{mSv} / \mathrm{hr}$ & $1,04 \times 10^{-4} \mathrm{mSv} / \mathrm{hr}$ & $0,216 \mathrm{mSv} / \mathrm{tahun}$ \\
\hline 4 & $\mathrm{D}$ & $3,46 \times 10^{-4} \mathrm{mSv} / \mathrm{hr}$ & $3,48 \times 10^{-4} \mathrm{mSv} / \mathrm{hr}$ & $0,725 \mathrm{mSv} / \mathrm{tahun}$ \\
\hline 5 & $\mathrm{E}$ & $3,57 \times 10^{-4} \mathrm{mSv} / \mathrm{hr}$ & $3,61 \times 10^{-4} \mathrm{mSv} / \mathrm{hr}$ & $0,75 \mathrm{mSv} / \mathrm{tahun}$ \\
\hline 6 & $\mathrm{~F}$ & $4,27 \times 10^{-4} \mathrm{mSv} / \mathrm{hr}$ & $4,31 \times 10^{-4} \mathrm{mSv} / \mathrm{hr}$ & $0,897 \mathrm{mSv} / \mathrm{tahun}$ \\
\hline
\end{tabular}

Setelah data hasil ukur pada tabel 5, 6 dan 7 didapat selanjutnya dibuat diagram grafik dengan menggunakan program microsoft excel dengan hasil sebagai berikut pada gambar 2 :

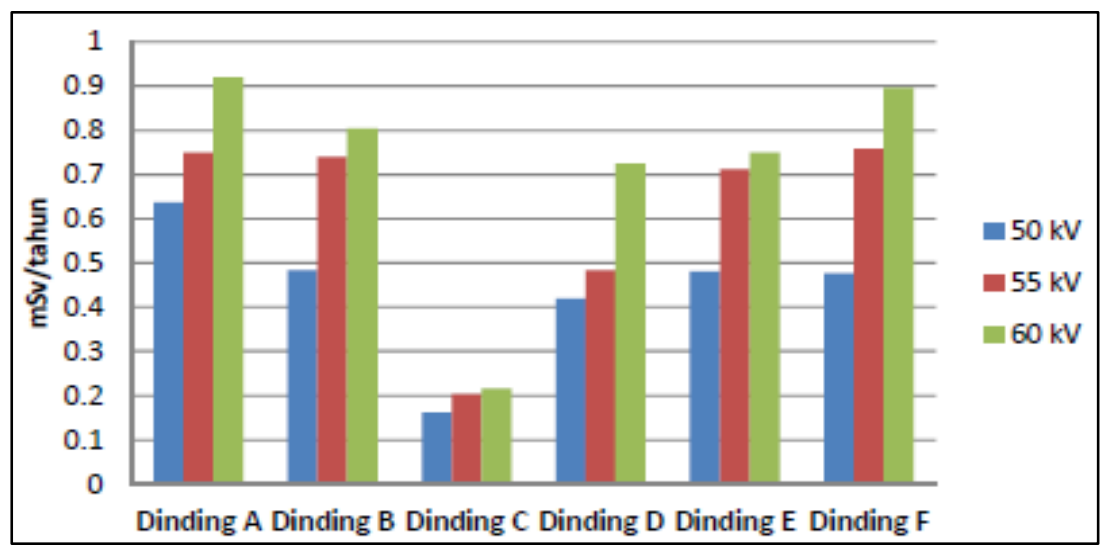

GAMBAR 2. Grafik Hasil Pengukuran Laju Dosis Radiasi Hambur

Setelah dilakukan pengukuran laju dosis radiasi hambur mobile $x$ ray merk SF100BY dengan menggunakan sumbe tegangan 50,55, dan $60 \mathrm{kV}$ dengan $16 \mathrm{mAs}$ maka didapat data yang tercantum di tabel 5.5, 5.6, dan 5.7 dengan dinding penahan titik A sampai dengan F. Hasil pengukuran dilakukan pengurangan dengan nilai dosis background mula-mula sebelum dilakukan eksposi dengan faktor eksposi yang telah ditentukan sehingga didapat nilai radiasi hamburan yang dikeluarkan oleh pesawat $x$-ray mobile menembus dinding maupun shielding 
kemudian selanjutnya dikalikan dengan faktor kalibrasi surveymeter dengan nilai kalibrasi 1,01. Dinding penahan di titik A dikategorikan penahan primer karena tube $x$-ray mengarah langsung ke dinding A.

Hasil analisis laju dosis hambur menggunakan tegangan $50 \mathrm{kV}$ dan $16 \mathrm{mAs}$ dengan alat surveymeter pada data tabel 5 menunjukan nilai minimum sebesar $0,77 \times 10^{-4} \mathrm{mSv} / \mathrm{hr}$ dan maksimum 2,29 x $10^{-4} \mathrm{mSv} / \mathrm{hr}$. Nilai laju dosis radiasi hambur untuk pertahun minimum 0,162 $\mathrm{mSv} / \mathrm{tahun}$ dan maksimum $0,477 \mathrm{mSv} / \mathrm{tahun}$. maka dibandingkan dengan nilai yang ditetapkan PERKA BAPETEN No. 4 Tahun 2013 bahwa NBD pekerja radiasi $20 \mathrm{mSv}$ dan masyarakat umum $1 \mathrm{mSv}$ maka nilai rata-rata tersebut masih jauh dibawah batas aman untuk pekerja radiasi maupun masyarakat umum.

Hasil analisis laju dosis hambur menggunakan tegangan $55 \mathrm{kV}$ dan $16 \mathrm{mAs}$ dengan alat surveymeter pada tabel 6 menunjukan nilai minimum sebesar $0,98 \times 10^{-4} \mathrm{mSv} / \mathrm{hr}$ dan maksimum $3,65 \times 10^{-4} \mathrm{mSv} / \mathrm{hr}$. Nilai laju paparan radiasi hambur untuk per tahun minimum 0,204 $\mathrm{mSv} / \mathrm{tahun}$ dan maksimum 0,76 mSv/tahun. Maka dibandingkan dengan NBD yang sudah ditetapkan masih jauh di bawah batas aman untuk pekerja radiasi maupun masyarakat umum.

Hasil analisis laju dosis hambur menggunakan tegangan $60 \mathrm{kV}$ dan $16 \mathrm{mAs}$ dengan alat surveymeter pada tabel 7 menunjukan nilai minimum sebesar $1,04 \times 10^{-4} \mathrm{mSv} / \mathrm{hr}$ dan maksimum $4,31 \times 10^{-4} \mathrm{mSv} / \mathrm{hr}$. Nilai laju dosis radiasi hambur untuk pertahun minimum $0,216 \mathrm{mSv} / \mathrm{tahun}$ dan maksimum 0,897 mSv/tahun. Maka dibandingkan dengan NBD yang sudah ditetapkan masih jauh di bawah batas aman untuk pekerja radiasi maupun masyarakat umum.

Dilanjutkan dengan hasil perhitungan yang sudah dilakukan menggunakan faktor eksposi 50,55, $60 \mathrm{kV}$ dan $16 \mathrm{mAs}$ dengan hasil pada tabel 5.5,5.6, dan 5.7 selanjutnya dibuat diagram grafik histogram ditunjukan pada gambar 5.2. mengamati dari tabel dan grafik dinding $\mathrm{C}$ memiliki laju dosis radiasi hambur paling kecil dibandingkan dengan dinding yang lain, karena dinding $\mathrm{C}$ posisi membelakangi arah dari tube $x$-ray yang mengarah ke dinding A. Selain itu, Dinding B, $\mathrm{D}$ dan $\mathrm{E}$ mempunyai dosis hambur yang berbeda hal ini menunjukan bahwa sebelah kiri pesawat $x$-ray mobile memiliki dosis radiasi hambur lebih besar dibandingkan sebelah kanan pesawat. Pada sebelah kiri pesawat merupakan posisi katoda yang mempunyai intensitas radiasi lebih besar dibandingkan anoda.

Terlihat pola kenaikan yang signifikan pada gambar 2 di titik F yang merupakan shielding di dalam ruangan untuk tempat berlindungnya petugas radiasi ketika melakukan pemeriksaan. Hal ini menunjukan nilai dosis hambur lebih besar ke arah shielding $\mathrm{F}$ dibandingkan dinding $\mathrm{B}, \mathrm{C}$, $\mathrm{D}$, dan E. Karena didalam ruangan pemeriksaan radiasi hambur pada dinding $\mathrm{F}$ akan ditambah dengan adanya hamburan dari dalam ruangan. Karena berkas sinar-X melalui suatu bahan atau suatu zat, maka berkas tersebut akan bertebaran ke segala arah, menimbulkan radiasi sekunder (radiasi hambur) pada bahan/zat yang dilaluinya.

Hasil analisis dari perhitungan yang sudah dilakukan untuk mengetahui radiasi bocor pada semua dinding, serta langit-langit diabaikan karena hasil perhitungan $\mathrm{n}$ bernilai negatif sehingga tidak diperlukan penahan untuk radiasi bocor pada pesawat. Dari hasil perhitungan, tebal dinding yang diperlukan masih lebih kecil dari pada tebal dinding yang terpasang di ruangan klinik radiologi medical check up. Dari hasil perhitungan dan pengukuran dengan surveymeter maka dinding penahan ruangan klinik radiologi dinyatakan aman bagi pekerja radiasi maupun masyarakat umum.

\section{KESIMPULAN}

Hasil analisis laju radiasi hambur dibelakang dinding penahan untuk tegangan $50 \mathrm{kV}$ dengan hasil $0,477 \mathrm{mSv} /$ tahun, tegangan $55 \mathrm{kV}$ dengan hasil $0,76 \mathrm{mSv} /$ tahun dan $60 \mathrm{kV}$ dengan hasil $0,897 \mathrm{mSv} /$ tahun. Hasil perhitungan tidak menunjukan adanya radiasi bocor pada semua dinding serta langit-langit karena hasil perhitungan $n$ bernilai $-3,808$ sehingga tidak diperlukan penahan untuk radiasi bocor pada pesawat. Pola sebaran radiasi hambur terlihat kenaikan yang signifikan pada dinding penahan yang merupakan shielding $\mathrm{F}$ yang terletak di dalam ruangan untuk tempat berlindungnnya petugas radiasi ketika melakukan pemeriksaan. Hal ini 
menunjukan radiasi hambur pada shielding $\mathrm{F}$ akan di tambah dengan adanya hamburan dari dalam ruangan.

\section{DAFTAR PUSTAKA}

[1] Bushong, S. C, 2008. "Radiologic Science For Technologist". Ninth Edition. Mosby Company, Missouri, USA.

[2] BAPETEN. 2013. "Surat Keputusan Kepala Bapeten nomor 4 tentang Proteksi dan Keselamatan Radiasi dalam Pemanfaatan Tenaga Nuklir". Jakarta.

[3] BATAN. 2005. "Desain Penahan Ruang Sinar-X". Pelatihan Petugas Proteksi Radiasi, Pusat Pendidikan dan Pelatihan Badan Tenaga Nuklir Nasional, Jakarta.

[4] Dradjat, A. N. 2010. "Analisis Sebaran Radiasi Hambur Dari Pasien Pada Pesawat Fluoroskopi Dengan Metode Monte Carlo dan Pengukuran". Universitas Indonesia. Jakarta.

[5] Sya'adah, Nunung, C. 2011. "Pengukuran Dosis Radiasi Sekunder Pada Pembuatan Foto Thorax Bagian Non Bedah Unit Gawat Darurat RSUD A. Wahab Sjahranie”. Universitas Mulawarman. Samarinda. Kalimantan Timur

[6] Syahria. 2012. "Pembuatan Kurva Isodosis Paparan Radiasi Di ruang Pemeriksaan Instalasi Radiologi RSUD Kabupaten Kolaka", Universitas Diponegoro, Semarang.

[7] Sutjipto, T. 2003. "Perancangan dan Penahan Radiasi di Unit Radiologi untuk Diagnostik Menggunakan Sinar X". Jurusan Teknik Nuklir Fakultas Teknik Universitas Gadjah Mada.

[8] Alatas, Zubaidah, dkk. 2014. "Buku Pintar Nuklir". Jakarta. BAPETEN RI

[9] Akhadi, M., 2000. "Dasar-Dasar Proteksi Radiasi", Edisi I, Rineka Cipta, Jakarta.

[10] DEPKES RI. 1999. "Pedoman Peningkatan Quality Assurance Fasilitas Pelayanan Radiologi". Jakarta

[11] Beiser, A. 1992. "Konsep Fisika Modern", Terjemahan The Houw Liong, Penerbit Erlangga, Jakarta.

[12] Bapeten, 2011. Keselamatan Radiasi Dalam Penggunaan Pesawat Sinar-X Radiologi Diagnostik Dan Intervensional. Jakarta: Bapeten.

[13] Chesney, H. 1971. "Radiographic Photography". 3th Edition, London. 